\title{
How Do Students' Mindsets in Learning Reflect their Cultural Values and Predict Academic Achievement?
}

\author{
Junfeng Zhang* \\ University of Helsinki \\ Helsinki, Finland \\ Elina Kuusisto \\ University of Humanistic Studies \\ Utrecht, Netherlands/ \\ University of Tallinn \\ Estonia, Tallinn \\ Kirsi Tirri \\ University of Helsinki \\ Helsinki, Finland
}

\begin{abstract}
Inspired by previous research indicating implicit beliefs about the malleability of human qualities, namely mindset, to affect learning outcomes, this article compares how Chinese and Finnish students' mindsets and attributions for success reflect their cultural values and predict their academic achievement. The study was conducted in one Chinese $(\mathrm{N}=705)$ and two Finnish $(\mathrm{N}=495)$ middle schools utilizing Dweck's mindset inventory, Weiner's attribution scale and students' school marks. The results illustrated that both Chinese and Finnish students held a growth mindset, and all identified the nature of intelligence as being more malleable than giftedness. However, Chinese students did not differentiate between intelligence and giftedness as clearly as Finnish students. Both students attributed the cause of their academic achievements to effort and ability, but placed more emphasis on effort. Furthermore, Chinese students' preference for effort significantly accounted for higher language marks, whereas Finnish students with fixed mindsets about giftedness achieved higher mathematics marks. Cultural interpretation, implications and limitations of the results were discussed.
\end{abstract}

Keywords: Mindset; intelligence; giftedness; attribution; academic achievement.

"Corresponding author: Junfeng Zhang, junfeng.zhang@helsinki.fi, zhouxixijay1991@gmail.com 


\section{Introduction}

One of the most highly debated topics in educational settings today deals with the feasibility of developing human intelligence. Theories that view intelligence as developmental and domain-specific usually maintain that intelligence can be cultivated (Gardner, 1999). Recent findings in brain research prove that the human brain can be exercised like a muscle in the body (Kujala \& Näätänen, 2010). This view of human intelligence is in accord with the incremental view of intelligence proposed by Carol Dweck (2000). However, conceptions of intelligence are always culture-dependent (Gardner, 1999), for which reason it is important to study them in their own cultural contexts. In other words, it is essential to study mindset from the perspective of different cultural values and worldviews.

In this study two quite different cultures representing eastern and western worldviews respectively - China's and Finland's - are discussed as background to this issue. Students across the two countries have notably been high achievers in the Programme for International Student Assessment (PISA). Yet the educational climates of these countries differ in how students are taught and how they develop intelligence. In China, since academic achievement is of central concern, schools and parents provide as much individualized instruction as possible, for example, through private tutoring (Ma, Jong, \& Yuan, 2013). In Finland students are educated in relatively integrative and inclusive learning environments, and the goal of education is the holistic development of the person, not simply cultivating their academic achievements only (Tirri \& Kuusisto, 2013). These differences have motivated us to investigate students' conceptions about learning and how their views predict their academic achievements in these two different educational cultures.

In recent decades mindset has appeared to be identified as a more and more important non-cognitive factor in explaining learning differences (Dweck, Walton, \& Cohen, 2014; Kuusisto, Laine, \& Tirri, 2017). As presented by Dweck (2000, 2017), mindsets are implicit beliefs that individuals hold about the malleability of their basic qualities and abilities. People with a fixed mindset believe that human qualities are static (the entity theory); those with a growth mindset are of the opinion that basic qualities can be developed through effort (the incremental theory). Mindset reveals how the simple idea of understanding the plasticity of the brain can foster learning. People with a growth mindset are inclined to embrace challenges and value effort, while those with a fixed mindset fear challenge and devalue effort. As a result, those of the incremental theory persuasion attain ever-higher levels of achievement, while those persuaded by the entity theory may achieve less than their full potential (Dweck, 2017).

Previous studies have shown that students' mindsets potentially play several roles in academic achievement, including being cause, mediator, and even outcome (Zhang, Kuusisto, \& Tirri 2017). In line with Dweck's theory, empirical research proves that mindset has the potential to influence various individual achievements, including academic, cognitive, affective, and socio-economic ones (Blackwell, Trzesniewski, \& Dweck, 2007; Burnette, O’Boyle, VanEpps, Pollack, \& Finkel, 2013). Studies conducted at different levels of schooling, such as 
primary school (Mueller \& Dweck, 1998), lower-secondary school (Blackwell et al., 2007), upper-secondary school (Claro, Paunesku, \& Dweck, 2016), and college (Aronson, Fried, \& Good, 2002), have proved that a growth mindset has the potential to predict academic achievement, while a fixed mindset may weaken a person's motivation and lead to lower achievements. Where the Chinese context is concerned, studies suggest that Chinese middle and high school students acknowledge intelligence as being changeable; additionally, the stronger a person's belief that intelligence can be changed and the more attention is paid to that endeavour, the higher the academic achievements that are realized (Wang \& Ng, 2012). By contrast, among Finnish primary and secondary school students, it has been found that a growth mindset about intelligence, but a fixed mindset about giftedness predicts higher marks in mathematics. Furthermore, Finnish students view the nature of intelligence as being more malleable than giftedness (Kuusisto et al., 2017) similar to the attitudes of American students (Makel, Snyder, Thomas, Malone, \& Putallaz, 2015).

However, some studies (Dupeyrat \& Mariné, 2005; Leondari \& Gialamas, 2002) have found the opposite results, suggesting that the correlation between mindset and achievement cannot be found or is not significant. These results have challenged the mindset theory and the instrument that Dweck has developed. In order to improve the reliability of Dweck's scale, the present study also uses Weiner's $(1979,1985)$ attributional theory. 'Attributions' are explanations of whether success or failure is caused by effort or ability. Effort indicates that individuals can control situations, while ability refers to fixed qualities. In studies of academic Olympians using Weiner's theory, the Finnish Olympians tend to attribute success and failure both to ability and to effort, and identify effort as being slightly more important for talent development than ability (Tirri, 2001). Similarly, the Taiwanese of China and the American Olympic participants attribute achievement more to effort than to ability (Feng, Campbell, \& Verna, 2001; Wu \& Chen, 2001), while the German participants attribute their achievements more to ability (Heller \& Lengfelder, 2000).

By comparing Dweck's and Weiner's theories, Hong, Dweck, Chiu, Lin \& Wan, (1999) revealed common properties shared by the two theories. Specifically, students with a growth mindset are more likely to attribute their failure to lack of effort and practice than are students with a fixed mindset. Those with a growth mindset are also inclined to take remedial action to attain higher achievement. Dweck's theory seems to go further and explain why a certain attribution is chosen; in other words, it attempts to explicate the mechanism behind individual behaviors, namely implicit beliefs. However, Dweck's implicit beliefs are not as concrete and intuitive as Weiner's attributions, especially when it comes to examining how mindsets predict performance. Hence, theoretically and empirically, it seems plausible that mindsets predict academic achievement by influencing the factors to which success is attributed. Accordingly, the present study aims to explore the following research questions:

1) How do Chinese and Finnish students view the nature of intelligence and of giftedness? 
2) To what do Chinese and Finnish students attribute their academic achievements?

3) How do Chinese and Finnish students' mindsets and attributions for success predict their academic achievements?

\section{Research contexts: The cultural worldviews and educational background of China and Finland}

This research was carried out in the contexts of the Chinese and Finnish educational systems, specifically among middle-school adolescents. These countries represent opposite cultural values and worldviews (Table 1) as identified by Hofstede, Hofstede, and Minkov (2010). These values and worldviews are discussed here from the perspective of education.

Table 1. Dimensions of cultures (based on Hofstede, Hofstede, \& Minkov, 2010).

\begin{tabular}{lll}
\hline Dimensions & China & Finland \\
\hline Power distance & Large & Small \\
\hline Individualism-collectivism & Collectivism & Individualism \\
\hline Indulgence-restraint & Restraint & Indulgence \\
\hline Masculinity-femininity & Masculinity & Femininity \\
\hline Long- and short-term orientation & Long-term & Short-term \\
\hline
\end{tabular}

\subsection{China}

Chinese culture has been identified with large power distance, meaning that authorities are respected and people accept a certain sense of inequality, yet feel that the use of power should be moderated by obligations (Hofstede et al., 2010, p. 80). One example of this power distance is the highest educational authority in China, the Ministry of Education, which formulates and issues educational policies and reforms through legislation, budget allocation, policy planning, and guidelines and also takes administrative measures (National Centre for Education Development Research, 2008). However, in recent years decentralization has been implemented gradually; for example, local authorities and educational organizations are encouraged to have more say in choosing textbooks and designing teaching. Among other features that distinguish it from Finland, China represents a collectivist culture, which is reflected in its patriotism and national pride. For instance, Chinese educational policy is orientated to be either culture-serving or country-serving and highlights China's long history and rich culture. This orientation may also explain why there are many subjects related to Chinese history, politics, and ideology at almost every educational level. Indeed, the restraint characteristic of Chinese culture could be understood more as an emphasis on strict ethical norms rather than gratification. For example, children are taught to treat others in a way they themselves would like to be treated, both at home and at school. 
Moreover, as a traditionally masculine culture, China has a clear distinction in emotional gender roles (Hofstede et al., 2010, p. 140), specifically men (vs women) are supposed to be assertive (vs modest), tough (vs tender) and focused on material success (vs quality of life). Fifth, according to Hofstede et al., (2010, p. 239), differentiation of long-term or short-term orientation depends on whether the fostering of virtues is orientated towards future rewards or towards past and present ones (Hofstede et al., 2010, p. 239). With this distinction China could be identified as having long-term orientation. Chinese culture nurtures virtues such as perseverance and thrift that are orientated towards the future. These virtues have often been cultivated in students destined for careers in the cultural sector. The perseverance feature also supports the finding that Asian cultures are effort-orientated (Dweck, 2000).

These cultural values can be interpreted from the perspective of Confucianism. As the central component of ancient Chinese culture at different stages in history, Confucian philosophy offers partial guidelines for individual Chinese behaviour still today (Qian, 2002; Hofstede et al., 2010, pp. 237-238). For example, traditionally Confucianism has emphasized the following: 1) respect for the hierarchy (large power distance); 2) the family as the prototype of the society as a whole (collectivism); 3 ) responsibility to society and ethical norms (restraint); 4) the central role of the male, in roles such as ruler, father, and husband (masculine feature); 5) patience and perseverance as well as hardworking (a long-term orientation).

\subsection{Finland}

By comparison with China, Finnish culture could be described as cultivating small power distances given that the ethos of equality has been the prevailing ideology since the 1960s (Räty \& Snellman, 1998). The basic principle of Finnish education can be described as 'Equal opportunity and high-quality education for all citizens' (the Ministry of Education and Culture \& the Finnish National Agency for Education, 2017). This has also meant the decentralization of education since the 1970s, meaning that most of the decision-making in education and the practical implementation of policies have been transferred to local authorities and schools; this includes such things as funding allocation and locally specific curricula as well as personnel recruitment. Finnish schools provide educational services based on their own arrangements, and teachers have the pedagogical freedom to choose textbooks and teaching methods for themselves (Gholami, Kuusisto, \& Tirri, 2015). Thus, it is easy to understand why curricula in different schools and regions of Finland are flexible.

Moreover, individualism has been one of the core values of Finnish educational policy since the 1990s (Kuusisto et al., 2017). Students are encouraged and helped in their holistic growth through the cultivation of transversal competences: thinking and learning-to-learn, cultural competence, life management, multiliteracy, ICT competence, working-life skills and civic involvement (Finnish National Board of Education, 2016). Finland has been described as an indulgent culture, meaning one that condones basic and natural human desires related to enjoying life and having fun (Hofstede et al., 2010; 
Gholami et al., 2015). In terms of education, Finnish indulgence can be seen from the relatively integrative, innovative, and inclusive learning environments that make learning pleasurable and in which holistic development along with academic performance is the main goal (Tirri \& Kuusisto, 2013). In Finland emotional gender roles overlap; both men and women are supposed to be modest and concerned with the quality of life (Hofstede et al., 2010, p. 140). Nevertheless, the majority of Finnish teachers are female. With regards to the differentiation between long- or short-term orientation as defined by Hosftede et al., (2010), Finnish short-term orientation could be explained by its educational and moral ethos, which is based on the heritage of Lutheran Christianity and emphasizes respect for the past and fulfilling present obligations (Hofstede et al., 2010, p. 269; Gholami et al., 2015).

In a word, the Finnish educational system endeavours to make high-quality education available for every student and ensure that each student develops holistically and individually. Schools provide special education to support students with learning difficulties. However, special education for academic high-achievers has not been on the agenda (Tirri \& Kuusisto, 2013). In accordance with this phenomenon, Finnish teachers have been found to regard the academic competence of poorly achieving students as malleable, but hold more fixed views of high achievers' competence (Kärkkäinen \& Räty, 2010; Rissanen, Kuusisto, Hanhimäki, \& Tirri, 2016). Studies indicate that the atmosphere in Finnish schools supports ideas of both a growth mindset and a fixed mindset, which seem to intertwine in everyday school life. However, the implementation of the National Core Curriculum for Basic Education 2014 (Finnish National Board of Education, 2016) will illustrate whether this phenomenon will be changed, as it emphasizes the individual development of all students, including the very gifted. Furthermore, teachers are encouraged not to compare students with each other, but rather to evaluate them based on their previous achievement in conformance to Dweck's (2000) ideas about how a growth mindset is supported.

The contrasts aside, there are interesting educational similarities between the Chinese and Finnish systems (Table 2). For example, both utilize a five-level structure from pre-school to higher education; both depend mainly on governmental funding with little involvement of private providers; both offer free tuition at the basic educational level. Finland's free policy applies to all levels of education up to university. However, at each level Chinese schools have subject teachers, whereas in Finland, primary schools have class teachers with subject teachers only in the higher grades. 
Table 2. Comparison of educational features in China and Finland

\begin{tabular}{lll}
\hline Items & China & Finland \\
\hline Structure & 1. Pre-school & 1. Pre-school \\
& 2. Primary school & 2. Primary school \\
& 3. Middle school & 3. Lower secondary education (with \\
& 4. High school \& Vocational & optional 10th year) \\
& education & 4. Upper secondary education \& \\
& 5. Higher education & Vocational education \\
& & 5. Higher education \\
\hline Power & Central $\longrightarrow$ Decentral & Decentral \\
\hline Curriculum & Uniform $\longrightarrow$ Flexible & Flexible \\
\hline Principle & Equality \& Culture-serving & Equality \& Individualism \\
\hline Reform priority & Balance \& Creativity & Holistic growth \& Transversal \\
& & competence \\
\hline Teachers & Subject teacher & Class teacher \& Subject teacher \\
\hline Funding & Government appropriation & Government appropriation \\
\hline Tuition & Free basic education & Free at all levels \\
\hline
\end{tabular}

\section{Data and Methods}

\subsection{Participants}

A probability sampling was collected from one Chinese middle school $(\mathrm{N}=705)$ and two Finnish (N=493) middle schools from 2017 to 2018. The Chinese school selected was located in a rural area and its educational level could be characterized as relatively low, while the two Finnish schools were from the Helsinki metropolitan area and represented higher educational levels. The mother tongue of all the Chinese students was Mandarin Chinese, while the mother tongue was Finnish for most of the Finnish students (75\%) (Table 3). Both samples had more male students than female $\left(\mathrm{N}_{\mathrm{Ch}}=381,54 \% ; \mathrm{N}_{\text {Fin }}=252\right.$, $51 \%)$ with ages ranging from 11 to $17\left(\mathrm{M}_{\mathrm{Ch}}=13.87, \mathrm{SD} 1.116 ; \mathrm{M}_{\mathrm{Fin}}=13.92\right.$, $\mathrm{SD}=.928)$. Finnish marks were given on a scale of 4 to 10 (4=fail, $5=$ lowest passing grade, $10=$ highest grade; $\mathrm{M}_{\text {Mother tongue }}=8.19, \mathrm{SD}=1.17 ; \mathrm{M}_{\text {Math }}=7.87$, $\mathrm{SD}=1.51$ ). For purposes of uniformity this study converted the original Chinese grading scale $(0-100,<60=$ fail, $60=$ lowest passing grade, $100=$ highest grade) to a Finnish equivalent (whereby $\mathrm{M}_{\text {Mother tongue }}=7.30, \mathrm{SD}=.72 ; \mathrm{M}_{\text {Math }}=6.43, \mathrm{SD}=1.36$ ).

Table 3. Students in China and Finland

\begin{tabular}{lll}
\hline & $\begin{array}{l}\text { China } \\
\mathrm{N}=705\end{array}$ & $\begin{array}{l}\text { Finland } \\
\mathrm{N}=493\end{array}$ \\
\hline Gender & & \\
Female & $324(46 \%)$ & $241(49 \%)$ \\
Male & $381(54 \%)$ & $252(51 \%)$ \\
\hline Mother tongue & & \\
Chinese & $705(100 \%)$ & $5(1 \%)$ \\
Finnish & 0 & $368(75 \%)$ \\
Other & 0 & $120(24 \%)$ \\
\hline Class & & \\
Grade 7 & $177(25 \%)$ & $183(37 \%)$ \\
Grade 8 & $228(32 \%)$ & $157(32 \%)$ \\
Grade 9 & $300(43 \%)$ & $152(31 \%)$ \\
\hline Academic achievement & $\mathrm{M}(\mathrm{SD})$ & $\mathrm{M}(\mathrm{SD})$ \\
Mother tongue & $7.30(.72)$ & $8.19(1.17)$ \\
Mathematics & $6.43(1.36)$ & $7.87(1.51)$ \\
\hline
\end{tabular}




\subsection{Instruments}

The questionnaire consisted of the following instruments: the Implicit Theory of Intelligence (ITI, Dweck, 2000), the Implicit Theory of Giftedness (ITG, Dweck, 2000; Kuusisto et al., 2017), and the Self-Confidence Attitude Attribute Scale (SaaS, Weiner, 1985; Campbell, 1996). As presented in Table 4, both ITI and ITG instruments included four statements about intelligence and giftedness respectively and used a 6-point Likert scale (1=strongly agree, 6=strongly disagree), with values of 1.0 to 3.5 indicating a fixed mindset and values of 3.6 to 6.0 indicating a growth mindset. With items shown in Table 5, the SaaS used a 5point Likert scale ( $1=$ strongly disagree, $5=$ strongly agree) and had seven items measuring how respondents explained their achievements.

Students' academic marks in their mother tongue and in mathematics were obtained from their autumn examination report in 2017. The Chinese marks were based on standardized tests, while Finnish marks were based on teachers' evaluations of the examinations and classroom activities. Further, in another Finnish school, seventh graders' academic achievement was assessed only verbally on a 5-point scale (lowest evaluation: 'You have not yet achieved your goals'; highest evaluation: 'You have achieved your goals excellently'). To ensure uniformity in this study, the measures were converted to a scale of 4 to 10 through data weighting.

\subsection{Procedure}

The Chinese data were gathered with a paper- and pencil- version of the questionnaire in the students' classrooms with the first author present to explain the procedure. The Finnish data were collected with an online questionnaire using Qualtrics software during school hours under teacher supervision. Across both countries students' marks were obtained from each school's administration office. In Finland consent for student participation was given by the city of Helsinki, the schools' administration, and the students' parents, while in China consent was given by the school administration.

\section{Results}

To answer the first question - 'How do Chinese and Finnish students view the nature of intelligence and of giftedness?' - Principal component analyses for ITI and ITG were conducted for Chinese and Finnish students separately. With the assumption that ITI and ITG were correlated, this study utilized direct oblimin rotation. Both at the Kaiser Meyer-Olkin level $\left(\mathrm{KMO}_{\mathrm{Ch}}=.870 ; \mathrm{KMO}_{\text {Fin }}=.879\right)$ and the determinant value (Determinant ${ }_{\mathrm{Ch}}=.084$; Determinant ${ }_{\mathrm{Fin}}=.002$ ), the sampling adequacy was proved to be meritorious. According to the scree plot of the Chinese sample, only one factor had eigenvalues over Kaiser's criterion of 1, which explained $47.05 \%$ of the variance. However, the Finnish sample appeared as a two-factor structure, which explained $80.16 \%$ of the variance. Factor loadings for the Chinese sample varied from .648 to .737, while the Finnish sample was between .868 and .938 . The internal consistency reliability was checked with Cronbach's alpha values. As Chinese students did not differentiate ITI from ITG, all eight items were combined into one variable with Cronbach's alpha value .838, which indicated good consistency (Chen, 2014). Further, the alpha values of the Chinese data were also calculated separately for intelligence 
$(\alpha=.766)$ and giftedness $(a=.713)$ for further analysis. For the Finnish sample Cronbach's alpha value $\left(\mathrm{a}_{\mathrm{ITI}}=.907, \mathrm{a}_{\mathrm{ITG}}=.927\right)$ could be identified as excellent (Chen, 2014).

Since the mean scores of each item were above 3.5 as noted in Table 4, students in the two samples appeared to have a growth mindset. A t-test for independent samples $\left(\mathrm{t}(863.957)=-5.009, \mathrm{p}=.000, \mathrm{\eta}^{2=}=.028\right)$ proved that Chinese students $(\mathrm{M}=3.98, \mathrm{SD}=1.03)$ had significantly higher scores for giftedness than Finnish students $(\mathrm{M}=3.61, \mathrm{SD}=1.37)$. However, no significant difference $(\mathrm{t}(935.245)=-$ 1.262, $\left.\mathrm{p}=.207, \mathrm{\eta}^{2}=.002\right)$ was established for perceptions about the nature of intelligence between the two samples $\left(\mathrm{M}_{\mathrm{Ch}}=4.16, \mathrm{SD}=1.07 ; \mathrm{M}_{\mathrm{Fin}}=4.08, \mathrm{SD}=1.28\right)$. Generally, both Chinese and Finnish students identified the nature of intelligence as being more malleable than giftedness with paired-sample $t$ test $\left(\mathrm{t}_{\mathrm{Ch}}(704)=5.730, \mathrm{p}=.000, \mathrm{\eta}^{2}=.045 ; \mathrm{t}_{\text {Fin }}(492)=8.140, \mathrm{p}=.000, \mathrm{\eta}^{2}=.119\right)$.

Table 4. Factor structure of Implicit Theories of Intelligence (ITI) and Giftedness (ITG)

\begin{tabular}{|c|c|c|c|c|}
\hline \multirow[b]{2}{*}{ Item } & \multirow{2}{*}{$\begin{array}{l}\text { Descriptive } \\
\mathrm{N}=705<N=493> \\
\mathbf{M}(\mathrm{SD})\end{array}$} & \multicolumn{3}{|c|}{ Principal component analysis } \\
\hline & & Factor 1 & Factor 2 & $h^{2}$ \\
\hline Mindset about intelligence (ITI) & $\begin{array}{l}4.16(1.068) a=.766 \\
<4.08(1.276) a=.907>\end{array}$ & & & \\
\hline (1) You have a certain amount of & $4.44(1.345)$ & .673 & & .453 \\
\hline $\begin{array}{l}\text { intelligence, and you really can't do } \\
\text { much to change it. }\end{array}$ & $<4.14(1.492)>$ & $<-.025>$ & $<.905>$ & $<.796>$ \\
\hline (2) Your intelligence is something that & $3.85(1.327)$ & .697 & & .486 \\
\hline you can't change very much. & $<3.95(1.373)>$ & $<.016>$ & $<.868>$ & $<.768>$ \\
\hline (3) To be honest, you can't really change & $4.29(1.396)$ & .737 & & .543 \\
\hline how intelligent you are. & $<4.23(1.469)>$ & $<.017>$ & $<.886>$ & $<.802>$ \\
\hline (4) You can learn new things, but you & $4.08(1.498)$ & .726 & & .527 \\
\hline $\begin{array}{l}\text { can't really change your basic } \\
\text { intelligence. }\end{array}$ & $<3.98(1.437)>$ & $<-.002>$ & $<.873>$ & $<.760>$ \\
\hline Mindset about giftedness (ITG) & $\begin{array}{l}3.98(1.033) a=.713 \\
<3.61(1.373) a=.927>\end{array}$ & & & \\
\hline (1) You have a certain amount of & $3.92(1.409)$ & .666 & & .444 \\
\hline $\begin{array}{l}\text { giftedness, and you really can't do much } \\
\text { to change it. }\end{array}$ & $<3.64(1.537)>$ & $<.872>$ & $<.054>$ & $<.815>$ \\
\hline (2) Your giftedness is something that you & $3.62(1.350)$ & .681 & & .464 \\
\hline can't change very much. & $<3.54(1.479)>$ & $<.930>$ & $<-.030>$ & $<.835>$ \\
\hline (3) To be honest, you can't really change & $4.30(1.370)$ & .653 & & .427 \\
\hline how gifted you are. & $<3.74(1.549)>$ & $<.938>$ & $<-.041>$ & $<.839>$ \\
\hline (4) You can learn new things, but you & $4.08(1.506)$ & .648 & & .420 \\
\hline can't really change your basic giftedness. & $<3.54(1.500)>$ & $<.875>$ & $<.032>$ & $<.797>$ \\
\hline \multirow[t]{2}{*}{ Percentage of variance } & & 47.05 & & \\
\hline & & $<62.09>$ & $<18.07>$ & \\
\hline
\end{tabular}

Chinese data <Finnish data>

*Scale of 1-6, higher scores indicate the approach to a growth mindset; Chinese (vs Finnish) data have a one-factor category (vs two), so factor loading is a component (vs a pattern) matrix.

To answer the second question - 'To what do Chinese and Finnish students attribute their academic achievements?' - a principal component factor analysis for Weiner's scale was conducted in both samples. The Chinese Kaiser Meyer- 
Olkin $(\mathrm{KMO}=.721)$ measure was middling and the determinant (.398) was at a good level, while the Finnish sampling adequacy $(\mathrm{KMO}=.826$; determinant $=.101)$ was more meritorious. Based on the scree plot and eigenvalues, two factors, namely effort and ability, appeared in both samples, and each factor included exactly the same items. Factor loadings varied from .687 to .799 for China and from .601 to .843 for Finland, and the factors explained $52.75 \%$ and $61.63 \%$ of the variance respectively. Through reliability tests, Chinese students' alpha values in effort $(\alpha=.688)$ illustrated questionable internal consistency reliability, and the value in ability $(\alpha=.573)$ was indicated as poor. By contrast, the Finnish sample's alpha values in effort $(\alpha=.825)$ and ability $(\alpha=.625)$ illustrated good and questionable levels respectively.

Based on the mean scores through descriptive information and t-tests (Table 5), both Chinese and Finnish students attributed their school achievements more to effort than to ability $\left(\mathrm{t}_{\mathrm{Ch}}(704)=-44.167, \mathrm{p}=.000, \mathrm{\eta}^{2}=.735 ; \mathrm{t}_{\text {Fin }}(489)=-15.661, \mathrm{p}=.000\right.$, $\eta^{2}=.334$ ). Moreover, $t$-tests ( $\mathrm{t}_{\text {effort }}(788.724)=-7.726, \mathrm{p}=.000, \eta^{2}=.070 ; \mathrm{t}_{\text {ability }}(1193)=$ 15.637, $\left.\mathrm{p}=.000, \mathrm{n}^{2}=.170\right)$ showed that Chinese students had significantly higher preference for effort $(\mathrm{M}=4.02, \mathrm{SD}=.585)$, but lower preference for ability $(\mathrm{M}=2.22$, $\mathrm{SD}=.805)$ than Finnish students ( $\mathrm{M}_{\text {Effort }}=3.67, \mathrm{SD}=.873$ ); $\mathrm{M}_{\mathrm{Ability}}=2.98, \mathrm{SD}=.857$ ). Hence, Chinese and Finnish students differed in their attributions for success.

Table 5. Factor structure of Self-Confidence Attribute Attitude Scale (SaaS)

\begin{tabular}{|c|c|c|c|c|}
\hline \multirow[b]{2}{*}{ Item } & \multirow{2}{*}{$\begin{array}{l}\text { Descriptive } \\
\mathrm{N}=705<N=493> \\
\mathbf{M}(\mathrm{SD})\end{array}$} & \multicolumn{3}{|c|}{ Principal component analysis } \\
\hline & & Factor 1 & Factor 2 & $\mathbf{h}^{2}$ \\
\hline Effort & $\begin{array}{l}4.02(.585) a=.688 \\
<3.67(.873) a=.817>\end{array}$ & Effort & Ability & \\
\hline $\begin{array}{l}\text { (1) My school achievement would be } \\
\text { better if I tried harder. }\end{array}$ & $\begin{array}{l}3.99(.824) \\
<3.87(1.020)>\end{array}$ & $\begin{array}{l}.707 \\
<.793>\end{array}$ & $\begin{array}{l}-.019 \\
<-.071>\end{array}$ & $\begin{array}{r}.505 \\
<.597>\end{array}$ \\
\hline $\begin{array}{l}\text { (2) I have to work hard to get good } \\
\text { marks. }\end{array}$ & $\begin{array}{l}4.06(.788) \\
<3.53(1.117)>\end{array}$ & $\begin{array}{l}.728 \\
<.749>\end{array}$ & $\begin{array}{l}-.004 \\
<.140>\end{array}$ & $\begin{array}{r}.528 \\
<.648>\end{array}$ \\
\hline $\begin{array}{l}\text { (3) I could do better in mathematics } \\
\text { if I worked harder. }\end{array}$ & $\begin{array}{l}3.94(.869) \\
<3.66(1.102)>\end{array}$ & $\begin{array}{l}.743 \\
<.832>\end{array}$ & $\begin{array}{l}-.024 \\
<-.017>\end{array}$ & $\begin{array}{r}.546 \\
<.684>\end{array}$ \\
\hline $\begin{array}{l}\text { (4) Hard work is the key to getting } \\
\text { good marks. }\end{array}$ & $\begin{array}{l}4.10(.774) \\
<3.62(1.103)>\end{array}$ & $\begin{array}{l}.697 \\
<.817>\end{array}$ & $\begin{array}{l}-.010 \\
<-.006>\end{array}$ & $\begin{array}{r}.488 \\
<.664> \\
\end{array}$ \\
\hline Ability & $\begin{array}{l}2.22(.805) \alpha=.573 \\
<2.98(.857) a=.625>\end{array}$ & & & \\
\hline $\begin{array}{l}\text { (5) There are some learning } \\
\text { assignments I cannot complete, no } \\
\text { matter how hard I try. }\end{array}$ & $\begin{array}{l}2.45(1.123) \\
<3.38(1.187)>\end{array}$ & $\begin{array}{l}.054 \\
<.223>\end{array}$ & $\begin{array}{l}.687 \\
<.601>\end{array}$ & $\begin{array}{r}.489 \\
<.496>\end{array}$ \\
\hline $\begin{array}{l}\text { (6) Being smart is more important for } \\
\text { school success than working hard. }\end{array}$ & $\begin{array}{l}2.05(1.084) \\
<2.92(1.052)>\end{array}$ & $\begin{array}{l}.034 \\
<-.058>\end{array}$ & $\begin{array}{l}.799 \\
<.780>\end{array}$ & $\begin{array}{l}.630 \\
<.582>\end{array}$ \\
\hline $\begin{array}{l}\text { (7) When I do poorly at school, it is } \\
\text { because I do not have the necessary } \\
\text { ability. }\end{array}$ & $\begin{array}{l}2.17(1.080) \\
<2.66(1.155)>\end{array}$ & $\begin{array}{l}.019 \\
<-.063>\end{array}$ & $\begin{array}{l}.715 \\
<.843>\end{array}$ & $\begin{array}{r}.507 \\
<.681>\end{array}$ \\
\hline Percentage of variance & & $\begin{array}{l}32.21 \\
<43.45>\end{array}$ & $\begin{array}{l}20.55 \\
<18.18>\end{array}$ & \\
\hline
\end{tabular}


Table 6 shows all correlations between ITI, ITG, SaaS, age, gender, and academic achievement. Next, only statistically significant correlations with academic achievement are reported. Firstly, weak $(r<.3)$ but statistically significant correlations were applicable between both ITI and academic achievement (Mother tongue: $\mathrm{r}_{\mathrm{Ch}}=.283, \mathrm{r}_{\mathrm{Fin}}=.200$; Mathematics: $\mathrm{r}_{\mathrm{Ch}}=.182, \mathrm{r}_{\mathrm{Fin}}=.163 ; \mathrm{p}<.01$ ). ITG and academic achievement correlated significantly but weakly $(\mathrm{r}<.3)$ only in the Chinese data $\left(r_{\text {mother tongue }}=.259, r_{\text {math }}=.206, \mathrm{p}<.01\right)$. Secondly, the respondents marks in both areas were negatively correlated with attribution to abilities (SaaS) across two samples (China: $r_{\text {mother tongue }}=-.259, r_{\text {math }}=-.216, p<.01$; Finland: $r_{\text {mother }}$ tongue $\left.=-.236, \mathrm{r}_{\text {math }}=-.225, \mathrm{p}<.01\right)$, and only Chinese students' attribution in effort (Saas) was associated with academic achievement $\left(r_{\text {mother tongue }}=.203, r_{\text {math }}=.177\right.$, $\mathrm{p}<.01$ ). Hence, scientifically significant but not very high correlations between the mindset as well as attribution and academic achievement verified that regression analysis with the chosen variables was possible (Chen, 2014).

Table 6. Bivariate Pearson correlations

\begin{tabular}{lllllll}
\hline & ITI & ITG & Effort & Ability & $\begin{array}{l}\text { Mother } \\
\text { tongue }\end{array}$ & Math \\
\hline ITI & & $.550^{* *}$ & $.226^{* *}$ & -.002 & $.200^{* *}$ & $.163^{* *}$ \\
ITG & $.670^{* *}$ & & $.114^{*}$ & -.075 & .064 & .005 \\
Effort & $.134^{* *}$ & $.159^{* *}$ & & $.368^{* *}$ & -.022 & -.033 \\
Ability & $-.318^{* *}$ & $-.307^{* *}$ & $-.188^{* *}$ & & $-.236^{* *}$ & $-.225^{* *}$ \\
Mother tongue & $.283^{* *}$ & $.259^{* *}$ & $.203^{* *}$ & $-.259^{* *}$ & & $.745^{* *}$ \\
Math & $.182^{* *}$ & $.206^{* *}$ & $.177^{* *}$ & $-.216^{* *}$ & $.572^{* *}$ & \\
\hline
\end{tabular}

Chinese data are given below the hypotenuse; Finnish data above and in italics

To answer the third question - 'How do Chinese and Finnish students' mindsets and attributions for success predict their academic achievement?' - a regression analysis with the Enter method was conducted separately. As shown in Table 7, ITI, effort, and ability predicted the marks in the mother tongue among Chinese students $\left(\mathrm{R}^{2}=.131, \mathrm{~F}(4,690)=27.148, \mathrm{p}<.001\right)$ while ITI and ability among Finnish students $\left(\mathrm{R}^{2}=.091, \mathrm{~F}(4,428)=11.854, \mathrm{p}<.001\right)$. Having a growth mindset for intelligence predicted higher marks in the mother tongue $\left(\beta_{\mathrm{Ch}}=.161, \mathrm{t}(690)=3.340\right.$, $\left.\mathrm{p}<.01 ; \beta_{\text {Fin }}=.240, \mathrm{t}(428)=4.325, \mathrm{p}<.001\right)$ for all students. In addition, both Chinese and Finnish students' preference for attributing achievements to ability significantly accounted for lower marks in the mother tongue $\left(\beta_{\mathrm{Ch}}=-.158, \mathrm{t}(690)=-\right.$ 4.144, $\left.\mathrm{p}<.001 ; \beta_{\mathrm{Fin}}=-.245, \mathrm{t}(428)=-5.025, \mathrm{p}<.001\right)$, whereas Chinese students' effort significantly accounted for higher language marks $(\beta=.141, \mathrm{t}(690)=3.903, \mathrm{p}<.001)$.

Different models predicted mathematics marks among Chinese students $\left(\mathrm{R}^{2}=.079, \mathrm{~F}(4,690)=15.919, \mathrm{p}<.001\right)$ and Finnish students $\left(\mathrm{R}^{2}=.083, \mathrm{~F}(4\right.$, $467)=11.644, p<.001)$. A growth mindset about intelligence $(\beta=.234, p<.001)$ but a fixed mindset about giftedness $(\beta=-.140, \mathrm{t}(690)=-2.662, \mathrm{p}<.01)$ predicted higher mathematics marks among Finnish students. By contrast, among the Chinese students a growth mindset only towards giftedness was associated with better 
mathematics marks $(\beta=.110, \mathrm{t}(690)=2.224, \mathrm{p}<.05)$. Both Chinese $(\beta=-.144, \mathrm{t}(690)=-$ $3.673, p<.001)$ and Finnish $(\beta=-.240, t(690)=-5.044, p<.001)$ students' tendency to attribute their achievements to ability accounted for lower marks in maths. However, a preference for effort contributed to higher marks in maths only among the Chinese students $(\beta=.127, \mathrm{t}(690)=3.413, \mathrm{p}<.01)$.

Table 7. Regression analyses for predictors of academic achievement

\begin{tabular}{|c|c|c|c|c|c|c|}
\hline & \multicolumn{3}{|c|}{ Mother tongue } & \multicolumn{3}{|c|}{ Mathematics } \\
\hline & B & $\beta$ & $\Delta R^{2}$ & B & $\beta$ & $\Delta \mathbf{R}^{2}$ \\
\hline & & & $.131^{* * *}$ & & & $.079 * * *$ \\
\hline & & & $<.091^{* * *}>$ & & & $<.083^{* * *}>$ \\
\hline \multirow[t]{2}{*}{ ITI } & 1.822 & $.161^{* *}$ & & .969 & .046 & \\
\hline & $<.223>$ & $<.240^{* * *}>$ & & $<.279>$ & $<.234^{* * *}>$ & \\
\hline \multirow[t]{2}{*}{ ITG } & .933 & .080 & & 2.419 & $.110^{*}$ & \\
\hline & $<-.070>$ & $<-.082>$ & & $<-.154>$ & $<-.140^{* *}>$ & \\
\hline \multirow[t]{2}{*}{ Effort } & 2.918 & $.141^{* * *}$ & & 4.929 & $.127^{* *}$ & \\
\hline & $<.013>$ & $<.009>$ & & $<.024>$ & $<.014>$ & \\
\hline \multirow[t]{2}{*}{ Ability } & -2.356 & $-.158^{\star \star *}$ & & -4.032 & $-.144^{\star * *}$ & \\
\hline & $<-.342>$ & $<-.245^{* * *}>$ & & $<-.425>$ & $<-.240^{* * *}>$ & \\
\hline
\end{tabular}

\section{Discussion}

This study compared how Chinese and Finnish students view the nature of intelligence and giftedness, to what they attribute their success, and whether or how these mindsets and attributions reflected their cultural values and predicted academic achievement. Data were gathered from one Chinese middle school $(\mathrm{N}=705)$ and two Finnish middle schools $(\mathrm{N}=493)$, so this study was a cross-cultural investigation with respect to different cultural values and worldviews.

Firstly, both Chinese and Finnish students were found to have a growth mindset, and they all identified the nature of intelligence as being more malleable than giftedness. This result was in accord with prior studies of Finnish schoolchildren and adolescents (Kuusisto et al., 2017) and of American high school students (Makel et al., 2015). No significant difference was established for perceptions of intelligence between Chinese and Finnish students. However, Chinese students did not differentiate between the nature of intelligence and giftedness in the same way as Finnish students.

Secondly, when students' attributions for their achievements were studied with Weiner's instrument, exactly the same two attributions were found in both China and Finland: effort and ability. Both Chinese and Finnish students relied more on effort than on their ability in order to perform better academically. Chinese students put more emphasis on effort than do Finnish students, who put slightly more emphasis on ability than do their Chinese peers. Such results bore out prior findings among Finnish Olympians, who attributed achievement 
to both effort and ability, while Chinese Taiwanese Olympians attributed their performance more directly to effort (Tirri, 2001; Wu \& Chen, 2011).

Thirdly, the study results suggest that mindsets were influential on students' academic achievement. Better marks in their mother tongue was predicted by both Chinese and Finnish students who had a growth mindset about intelligence. Both in China and Finland, a preference for ability over effort significantly predicted lower marks in the mother tongue and mathematics, while Chinese students' preference for effort significantly accounted for higher marks in both subjects.

To conclude, this study has illustrated both similarities and differences in Chinese and Finnish students' mindsets with regard to academic achievement. In terms of similarity, both groups: 1) held a growth mindset and identified the nature of intelligence as being more malleable than giftedness; 2) attributed the cause of their academic achievements to effort and ability, but placed more emphasis on effort; 3) a growth mindset about intelligence predicted higher mother tongue marks, while less preference for ability as an achievement attribution predicted higher marks in both mother tongue and mathematics.

As for the differences: 1) Chinese students did not differentiate between the nature of intelligence and giftedness, but Finnish students did; 2) Chinese students put more emphasis on effort than do Finnish students, whose emphasis on ability scored slightly higher than that of their Chinese peers; 3) Chinese students' preference for effort in attributing achievement significantly predicted higher mother tongue and mathematics marks, while Finnish students' fixed mindset about giftedness predicted higher mathematics marks.

Different cultural climates and worldviews may explain the differences in these results. As outlined earlier, Asian cultures have been recognized as effortorientated (Dweck, 2000; Hofstede et al., 2010; Wang \& Ng, 2012; Wu \& Chen, 2001). For example, the indigenous precept among the Chinese - 'making an effort to compensate for inadequate intelligence' (qín néng bǔ zhuō) - illustrates the emphasis on hard work. This could explain why Chinese students prefer to attribute learning achievement more to effort than to ability. Meanwhile, this attitude enables Chinese students to focus more on endeavour. In addition, it has been found that students from long-term orientation cultures are more talented in the applied and concrete sciences than in the theoretical and abstract sciences (Hofstede et al., 2010, p. 275). This might explain why the students in the present study assimilated the concepts of intelligence and giftedness.

In cultures with a short-term orientation such as Finland students tend to attribute success and failure to luck and to show talent in theoretical and abstract sciences (Hofstede et al., 2010, p. 275). This might explain why Finnish students emphasized ability more in academic achievement, similar to German students (Heller \& Lengfelder, 2000), and why Finnish students differentiate the nature of intelligence and giftedness more clearly than the Chinese students. Further, there appear to be two cultures in the Finnish educational system: a culture supporting everyone's development and a culture acknowledging giftedness as 
being associated with fixed qualities (Dweck, 2009; Kärkkäinen \& Räty, 2010; Rissanen et al., 2016; Räty \& Snellman, 1998). This may explain why Finnish students' fixed mindset about giftedness predicted higher mathematics marks.

This study has both theoretical and practical implications. Theoretically, we investigated Dweck's theory about mindset and Weiner's theory about attribution in two different educational contexts. The results of this crossnational, comparative research provide empirical support for the reliability and the validity of the two instruments. For teaching and learning practice, the results confirm that a growth mindset is linked with higher grades, while attributing achievement more to effort and less to ability seems to improve learning. For teachers, it is worth cultivating a growth mindset among students, while students should be encouraged to value effort and develop a growth mindset to improve their performance at school.

Particularly noteworthy are the very different cultural values and worldviews in which this cross-cultural, empirical investigation exploring students' mindsets and their role in predicting academic achievement was conducted. To the authors' knowledge, it is the first study to compare Finnish and Chinese students' mindsets. Yet despite the moderate, even high, effect sizes, this case study was carried out in only three middle schools and thus cannot be generalized to all Chinese and Finnish students. Moreover, there seems to be an educationally imbalanced sample, as the selected Chinese school, which was in a rural area, did not correspond academically to the selected Finnish schools, which were in metropolitan areas. Similar academic levels and more samples from different cultural contexts are needed to conduct generalized and in-depth research in the future. Furthermore, apart from the horizontal investigation at a single time, longitudinal research, including interventions, would be ideal for determining whether and how a changed mindset affects academic achievement from a long-term perspective.

\section{References}

Aronson, J., Fried, C. B., \& Good, C. (2002). Reducing the effects of stereotype threat on African American College students by shaping theories of intelligence. Journal of Experimental Social Psychology, 38(2), 113-125. doi:10.1006/jesp.2001.1491

Blackwell, L. S., Trzesniewski, K. H., \& Dweck, C. S. (2007). Implicit theories of intelligence predict achievement across an adolescent transition: A longitudinal study and an intervention. Child Development, 78(1), 246-63. doi:10.1111/j.14678624.2007.00995.x

Burnette, J. L., O'Boyle, E. H., VanEpps, E. M., Pollack, J. M., \& Finkel, E. J. (2013). MindSets matter: A meta-analytic review of implicit theories and self-regulation. Psychological Bulletin, 139(3), 655-701. doi:10.1037/a0029531

Campbell, J. R. (1996). Developing cross-national instruments: Using cross-national methods and procedures. International Journal of Educational Research, 21(7), 675684. doi:10.1016/S0883-0355(97)86727-4

Chen, Z. C. (2014). SPSS 与统计分析 [SPSS and statistic analysis]. Beijing: Educational Science Publishing House. 
Claro, S., Paunesku, D., \& Dweck, C. S. (2016). Growth mindset tempers the effects of poverty on academic achievement. Proceedings of the National Academy of Sciences, 113(31), 8664-68. doi:10.1073/pnas.1608207113

Dupeyrat, C., \& Mariné, C. (2005). Implicit theories of intelligence, goal orientation, cognitive engagement, and achievement: A test of Dweck's model with returning to school adults. Contemporary Educational Psychology, 30(1), 43-59. doi:10.1016/j.cedpsych.2004.01.007

Dweck, C. S. (2000). Self-theories: Their role in motivation, personality, and development. New York: Psychology Press.

Dweck, C. S. (2009). Self-theories and lessons for giftedness: A reflective conversation. In T. Balchin, B. Hymer, \& D. J. Matthews (Eds.), the Routledge International Companion to Gifted Education (pp. 308-316). London, UK: Routledge.

Dweck, C. S. (2017). Mindset: Changing the Way You Think to Fulfil Your Potential. London: Hachette UK.

Dweck, C. S., Walton, G. M., \& Cohen, G. L. (2014). Academic tenacity: mindsets and skills that promote long-term learning. Bill \& Melinda Gates Foundation.

Feng, A. X., Campbell, J. R., \& Verna, M. A. (2001). The talent development of American physics Olympians. Gifted and Talented International, 16(2), 108-114. doi: 10.1080/15332276.2001.11672972

Finnish National Board of Education. (2016). National Core Curriculum for Basic Education 2014. Helsinki: National Board of Education.

Gardner, H. (1999). Intelligence reframed: Multiple intelligences for the 21st century. London: Hachette UK.

Gholami, K., Kuusisto, E., \& Tirri, K. (2015). Is ethical sensitivity in teaching culturally bound? comparing Finnish and Iranian teachers' ethical sensitivity. Compare, 45(6), 886-907. doi:10.1080/03057925.2014.984588

Heller, K., \& Lengfelder, A. (2000). German Olympiad study on mathematics, physics and chemistry. Paper presented at annual meeting of American Educational Research Association, New Orleans, USA.

Hofstede, G., Hofstede, G. J., \& Minkov, M. (2010). Cultures and Organizations: Software of the Mind. 3rd ed. New York: McGraw-Hill.

Hong, Y. Y., Dweck, C. S., Chiu, C.Y., Lin, D. M.S., \& Wan, W. (1999). Implicit theories, attributions, and coping: a meaning system approach. Journal of Personality and Social Psychology, 77(3), 588-99. doi:10.1037/0022-3514.77.3.588

Kärkkäinen, R., \& Räty, H. (2010). Parents' and teachers' views of the child's academic potential. Educational Studies, 36(2), 229-232. doi:10.1080/03055690903162424

Kujala, T., \& Näätänen, R. (2010). The adaptive brain: a neurophysiological perspective. Progress in Neurobiology, 91(1), 55-67. doi:10.1016/j.pneurobio.2010.01.006

Kuusisto, E., Laine, S. \& Tirri, K. (2017). How do school children and adolescents perceive the nature of talent development? A case study from Finland. Education Research International 2017, 1-8. doi:10.1155/2017/4162957

Leondari, A., \& Gialamas, V. (2002). Implicit theories, goal orientations, and perceived competence: impact on students' achievement behavior. Psychology in the Schools, 39(3), 279-91. doi:10.1002/ pits.10035

Ma, X., Jong, C., \& Yuan, J. (2013). Exploring reasons for the East Asian success in PISA. Chap. 10 in H. D. Meyer, \& A. Benavot (Eds.), the PISA, Power, and Policy: The Emergence of Global Educational Governance, (pp. 225-246). Oxford: Symposium Books. 
Makel, M. C., Snyder, K. E., Thomas C., Malone, P. S., \& Putallaz, M. (2015). Gifted students' implicit beliefs about intelligence and giftedness. Gifted Child Quarterly, 59(4), 203-12. doi:10.1177/0016986215599057

Ministry of Education and Culture \& Finnish National Agency for Education. (2017). Finnish Education in a Nutshell. Accessed on 01 January 2018. http://www.oph.fi/download/146428_Finnish_Education_in_a_Nutshell.pdf

Mueller, C. M., \& Dweck, C. S. (1998). Praise for intelligence can undermine children's motivation and performance. Journal of Personality and Social Psychology, 75(1), 33-52. doi:10.1037/0022-3514.75.1.33

National Centre for Education Development Research \& Chinese National Commission for UNESCO. (2008). National Report on Mid-Term Assessment of Education for All in China. http:// unesdoc.unesco.org/images/0020/002070/207018e.pdf

Qian, Mu. (2002). 论语新解 [New interpretation of lunyu]. Beijing: SDX Joint Publishing company.

Räty, H., \& Snellman, L. (1998). Social representations of educability. Social Psychology of Education, 1(4), 359-73. doi:10.1007/BF02335554

Rissanen, I., Kuusisto, E., Hanhimäki, E., \& Tirri, K. (2016). Teachers' implicit meaning systems and their implications for pedagogical thinking and practice: A case study from Finland. Scandinavian Journal of Educational Research, 1-14. doi: 10.1080/00313831.2016.1258667

Tirri, K. (2001). Finland Olympiad studies: what factors contribute to the development of academic talent in Finland. Educating Able Children, 5(2), 56-66.

Tirri, K., \& Kuusisto, E. (2013). How Finland serves gifted and talented pupils. Journal for the Education of the Gifted, 36(1), 84-96. doi:10.1177/0162353212468066

Wang, Q., \& Ng, F. F. Y. (2012). Chinese students' implicit theories of intelligence and school performance: implications for their approach to schoolwork. Personality and Individual Differences, 52(8), 930-35. doi:10.1016/j.paid.2012.01.024

Weiner, B. (1979). A theory of motivation for some classroom experiences. Journal of Educational Psychology, 71(1), 3-25. doi:10.1037/0022-0663.71.1.3

Weiner, B. (1985). An attributional theory of achievement motivation and emotion. Psychological Review, 92(4), 548-73. doi:10.1037/0033-295X.92.4.548

Wu, W. T., \& Chen, J. D. (2001). A follow-up study of Taiwan physics and chemistry Olympians: The role of environmental influences in talent development. Gifted and Talented International, 16(1), 16-26. doi:10.1080/15332276.2001.11672949

Zhang, J. F., Kuusisto, E., \& Tirri, K. (2017). How teachers' and students' mindsets in learning have been studied: research findings on mindset and academic achievement. Psychology, 8(9), 1363-77. doi:10.4236/psych.2017.89089 